\title{
Editorial
}

\section{Learning from Chernobyl to tackle the Covid-19 pandemic}

\author{
Marcel Bursztyn, Gabriela Litre, Patrícia Mesquita, Carlos Hiroo Saito
}

doi:10.18472/SustDeb.v12n1.2021.37692

In 1986, the severe accident at the Chernobyl nuclear power plant in the former Soviet Union occurred in a world still marked by the geopolitical division of the Cold War. Despite the tragedy, the opponents considered that any unfortunate event from "the other side" of the iron curtain was "their problem" and a setback. The devastating effects of the accident have spread throughout the European continent. This catastrophe showed that when dealing with environmental issues, there is no enemy territory nor borders.

The consequences of that accident inspired warnings and actions summed up in a document prepared by the World Commission on Environment and Development from the United Nations: the Bruntland Report ${ }^{1}$. This report served as a reference to the debates that would take place at the Rio-92 Conference. Published the year after the Chernobyl accident, the document Our Common Future inaugurates the concept of Sustainable Development. Besides, it pointed out there is no point in seeking to solve environmental challenges in the sphere of a single country even if nations own different interests and unequal shares of responsibility. When it comes to our habitat, we humans, living and being part of ecosystems, must consider planet Earth as a whole. The idea was not exactly new: two decades earlier, Kenneth Boulding ${ }^{2}$ had already pointed out that we are all passengers of the same spaceship, Earth. If the ship suffers an accident, we will all be vulnerable. Even if we sail safely, some will enjoy the journey in first class, and others survive piled up in the cargo bay.

Chernobyl should have taught us it is not enough to take care of our garden if the neighbour's one suffers from exposure to weeds that will eventually affect ours. It's been 35 years, and today we face the Covid-19 pandemic.

As in the days of Chernobyl, the world still confronts similar challenges. At that time, scientists' warnings about the risks of a nuclear catastrophe were eclipsed by the short-term vision of cheaper energy production' economic benefits, even if much riskier. At practice, national selfishness prevailed. It prevailed the idea that it is up to each to take care of his/her backyard. Along with it, political arguments supported that economy cannot stop and is above other concerns, despite warnings that risks (even if invisible to the naked eye) do not respect political boundaries.

Boulding also warned us that economic reasoning should not overlap with the principle of Life (with a capital L) as humanity's dominant ethos. "ANYONE who believes that exponential growth can go on forever in a finite world is either a madman or an economist," he said in $1966^{3}$.

Escapism and negationism are direct or indirect consequences of this persistent short-term economic reason, in addition to political blindness and sectarian stupidity. Faced with the pandemic of Covid-19 that, as Chernobyl does not obey national borders, each country has been dealing in its

1 | World Commission on Environment and Development. Our Common Future. Oxford: Oxford University Press, 1987.

2 | Boulding, Kenneth E. The economics of the coming spaceship earth, Environmental Quality Issues in a Growing Economy, 1966.

3 | Kenneth Boulding, "The Economics of the Coming Spaceship Earth" (1966), in Victor D. Lippit, ed., Radical Political Economy, Armonk, NY: M.E. Sharpe. p 362 
way with the challenge; some with significant commitment and determination, others not. Some have bet on investing in science for vaccine development. Others have worked to ensure the early purchase of these vaccines. Some, however, preferred to adopt the ostrich's conduct, hiding the head in the hole for not facing the problem.

These are fragmented actions in a world where, despite its positive effects, interconnection has also proved to be threatening. Any local outbreak can soon become epidemic and even pandemic since globalisation does not regard only markets. There is also a large flow of people, immigrants or tourists, who circulate between continents. It is a phenomenon now evident in the public health sphere. It repeats processes that were already clear, such as ocean degradation, climate change or the different forms of cross-border pollution. Regardless of the origin or responsibility, damages tend to be more intense in the most vulnerable parts of the world. Those that are already socioeconomically unprotected suffer more.

A year after the outbreak of the Covid-19 pandemic, with Europe facing the third wave of the pandemic and Latin America the second, more lethal and contagious, the world panorama already permits us to identify some facts:

- The rapid spread around the world;

- Some countries reacted soon and deployed great efforts to avoid devastating consequences, with diverse results;

- Science was agile in directing efforts to vaccines and medicines research;

- More anticipated governments invested in the early purchase of vaccines, which did not always result in the contracted deliveries;

- There was a massive reduction in the international flow of people, which had the indirect consequence of the carbon footprint reduction;

- The concentration of the global pharmaceutical and hospital equipment industry in China exposed the geopolitical fragility of some countries in acquiring such products;

- The argument that sanitary barriers are antagonistic to economic progress proved to be fallacious since the non-adoption of such measures ends up causing even more substantial damage to production, employment and public accounts;

- Despite some governments' attempt to discredit or turn private the public health system, this one remains fundamental, both in the global south and in the wealthiest countries;

- It is better to be safe than sorry. It is more human and cheaper! It is more efficient and fairer to make access to solutions universal. It is cleverer to cooperate than compete, at least when it comes to common goods;

- Vaccines that ensure protection against the pandemic should not be goods, such as anything you buy or not in a store. In Elinor Ostrom's interpretation ${ }^{4}$, vaccines are a typical case of common goods to be guaranteed by respecting rights.

Sustainability in Debate - SeD, as an academic journal, has the scientific and ethical commitment to shed light on the relevance of these rights. While they represent social justice, they also contribute to a world that is not at the mercy of risks, such as the present pandemic.

4 | Ostrom, Elinor. Governing the Commons. The Evolution of Institutions for Collective Action. Cambridge University Press, 1990. 
The December 2020 issue of SeD presented a dossier studying these rights in four interconnected dimensions: food, water, energy, and socio-environmental security, under the guidance of the Nexus+ approach ${ }^{5}$.

Just as Chernobyl was not the last major nuclear accident - the Fukushima disaster hit the world in 2011 - other outbreaks and pandemics will likely happen. The most plausible way to avoid them or at least mitigate them is with precaution. We also need more investment in science to alert us every day about our global vulnerability and generate collective intelligence for new solutions' construction.

This edition of SeD features eight articles in the Varia section.

In the first article, Junkes et al. address the impact of quarantine measures in response to the Covid-19 pandemic on urban air pollution in the cities of São Paulo and Rio de Janeiro for two months in 2020. They observe a significant pollutants reduction related to social isolation if compared to the same period in 2019.

Then, Lindoso et al. and Racowski and al. address the sustainable development goals (SDGs). The first authors discuss the transparency and capacity of the Brazilian public information system, focusing on the potential for monitoring the national indicators of the SDG3 (health and well-being) on a municipal scale, a key topic in the Covid-19 health crisis context. Racowski et al. perform a diagnosis of the wheat and derivatives segment around the adoption/implementation of the Agenda 2030 and its SDGs to business practices, using a sample of 91 companies in Brazil.

The following three articles address different aspects of water resources. First, Litben studies the sustainability of a pre-Columbian water management system in Ecuador, comparing it to modern technologies used off the national coast.

The other two articles address the implementation of sustainability strategies through interventions in São Paulo universities and the implementation of sustainable urban infrastructures in Santa Catarina. In 2015, during a water crisis context, the Federal University of São Paulo took measures to reduce water consumption, which, according to Justi et al., would have helped academics to use water and financial resources more efficiently, making the institution more sustainable. Montag4ER"('a et al. assess the impacts of a permeable pavement integrated into the infiltration trenches in the hydrological processes of the city of Blumenau.

In a final block, Courdin discusses the coordinating process for collective actions among family ranchers on the northern coast of Uruguay. He demonstrates the processes are endogenous and exogenous, reflected in norms and learning processes and sharing rules. And finally, Dávanos, Rodrigues-Filho and Litre propose alternatives to transform the tacit indigenous knowledge of the Tuxá people about the impacts of dams on traditional communities into explicit and instrumental knowledge for policymaking. In this process, the authors retaught the balance between economic progress driven by renewable energy production in Brazil and the negative impact on the subsistence of one of the most socioenvironmentally vulnerable national communities.

We hope you are staying safe, if possible, and enjoy reading this issue!

5 | https://periodicos.unb.br/index.php/sust/issue/view/2174 